\title{
Using CR System at the Department of Radiation Oncology PACS Evaluation
}

\author{
Seungil Hong, Youngjae Kim \\ Dept. of Radiological Technology Gwangyang Health College

\section{방사선 종양학과에서 CR System을 이용한 PACS 유용성 평가}

\author{
홍성일, 김영재 \\ 광양보건대학교 방사선과
}

\begin{abstract}
Today each hospital is trend that change rapidly by up to date, digitization and introducing newest medical treatment equipment. So, we introduce new CR system and supplement film system's shortcoming and PACS, EMR, RTP system's network that is using in hospital harmoniously and accomplish quality improvement of medical treatment and service elevation about business efficiency enlargement and patient Accordingly, we wish to introduce our case that integrate reflex that happen with radiation oncology here upon to PACS using CR system and estimate the availability.

We measured that is Gantry, Collimator Star Shot, Light vs. Radiation, HDR QA(Dwell position accuracy) with Medical LINAC(MEVATRON-MX) Then, PACS was implemented on the digital images on the monitor that can be confirmed through the QA. Also, for cooperation with OCS system that is using from present source and impose code that need in treatment in each treatment, did so that Order that connect to network, input to CR may appear, did so that can solve support data mistake (active Pinacle's case supports DICOM3 file from present source but PACS does not support DICOM3 files.) of Pinacle and PACS that is Planning System and look at Planning premier in PACS.

All image and data constructed integration to PACS as can refer and conduct premier in Hospital anywhere using CR system. Use Dosimetry IP in Filmless environment and QA's trial such as Light/Radition field size correspondence, gantry rotation axis' accuracy, collimator rotation axis' accuracy, brachy therapy's Dwell position check is available.

Business efficiency by decrease and so on of unnecessary human strength consumption was augmented accordingly with session shortening as that integrate premier that is neted with radiation oncology using $\mathrm{CR}$ system to PACS. and for the future patient information security is essential.
\end{abstract}

Key Word : CR system, PACS, Filmless, Quality Assurance 


\section{요 야}

오늘날 의료영상매체의 획기적인 발전으로 각 병원에서 최신 의료장비를 도입함으로써 첨단화, 디지털화로 급변하 는 추세이다. 이러한 움직임에 발맞추어 방사선 종양학과에서도 CR system을 도입하여 film system의 단점을 보완하 고 병원에서 사용하고 있는 Picture Archiving and Communication System(PACS)과 Electronic Medical Record (EMR), 그리고 Radiation therapy Treatment Planning system(RTP)의 network를 원활히 하여 업무효율 증대 및 환자에 대한 의료의 질 개선과 서비스 향상을 이루고자 하고 있는데, 방사선 종양학과의 Computed Radiography system(CR system)을 이용하여 PACS에 통합한 사례를 소개하고 그 유용성을 평가하고자 한다.

의료용 선형가속기인 MEVATRON-MX를 이용하여 현재 시행하고 있는 정도관리 중 Gantry, Collimator Star Shot, Light vs. Radiation Field Accuracy, HDR QA(Dwell position accuracy)를 시행하여 PACS 상에 구현하였고 모 니터 상에서 디지털 영상을 통한 $\mathrm{QA}$ 가 가능한지 확인하였다. 또한, 현재 S병원에서 사용 중인 Operation Control System(OCS)과 연동하여 치료에 필요한 코드를 각각의 치료에 부과하여 네트워크로 연결, CR상에 입력한 order가 나타나도록 하였으며, Planning System인 Pinacle과 PACS상의 지원 data 오류를 해결하여 PACS 상에서도 Planning 영상을 볼 수 있도록 하였다.

CR system을 이용하여 L-gram, simulation image, planning image를 병원 내 어느 곳에서나 영상을 조회하고 볼 수 있게 PACS에 통합 구축되어있다. Filmless 환경에서 Dosimetry용 IP를 이용하여 Light/Radition field size 일치, gantry rotation axis의 정확성, collimator rotation axis의 정확성, brachy therapy의 Dwell position check등 QA의 시 행이 가능하였다.

$\mathrm{CR}$ system을 이용하여 방사선 종양학과에서 얻어지는 영상을 $\mathrm{PACS}$ 에 통합함으로써 작업시간 단축과 그에 따른 불필요한 인력소모의 감소 등으로 인하여 업무효율이 증대되었지만 향후 환자정보에 대한 보안을 필요로 한다.

중심단어: $\mathrm{CR}$ 시스템, PACS, Filmless, 정도관리

\section{I . 서론}

PACS 및 Electronic Medical Record(EMR) 등과 같은 프로토콜은 80 년대 중반이 되면서 상용화된 제품들이 출시되었으며 90년대 들어서는 적은 투자로 구현할 수 있으며 점진적으로 확장, 통합이 가능한 소형의 부분 적인 시스템 (mini-PACS)이 개발되었다. 90년대 후반에 는 mini-PACS의 성공적인 도입을 계기로 full-PACS 전 병원적인 규모로 확장하기 이르렀다 ${ }^{[1]}$.

오늘날에는 각 병원이 최신 의료장비를 도입함으로 써 첨단화, 디지털화로 급변하는 추세이며 이에 따라 관리해야하는 영상의 수가 기하급수적으로 증가하였 고 영상 확인과 판독에 짧은 시간을 필요로 하였다 ${ }^{[2]}$.

$\mathrm{PACS}$ 의 도입은 기존의 필름 제작 관련 재료비 및 관리비용을 절감할 수 있으며 인건비를 줄일 수 있고, 필름을 보관하는 데 필요한 공간적 영역을 줄일 수 있 는 장점이 있다. 또한 필름을 찾는데 걸리는 시간적인
소비, 빠른 영상 판독을 통한 고객 만족도 향상, 영상 분실을 방지하는 2 차적 이익이 있다 ${ }^{[3]}$.

방사선 종양학과는 영상의학과와는 상대적으로 관 리하는 영상의 수가 적었지만 방사선 치료기술이 발 전되어 감에 따라 관리하고 보관하여야 하는 영상의 수와 환자의 정보가 기하급수적으로 증가하고 있는 추세이다 ${ }^{[4]}$.

Electronic Medical Record(EMR) 시스템과 PACS의 연 동성을 통하여 업무 효율을 증대하고 $\mathrm{CR}$ system을 통 하여 film system의 단점을 보완, $\mathrm{S}$ 병원에서 사용하고 있는 PACS와 EMR, 그리고 RTP system의 network를 원 활히 하여 업무효율 증대 및 환자에 대한 의료의 질 개선과 서비스 향상을 이루고자 방사선 종양학과에서 발생하는 영상을 CR system을 이용하여 PACS에 통합 한 사례를 소개하고 본 논문에서 그 유용성을 평가하 고자 한다. 


\section{II. 실험 기기 및 방법}

\section{1. 실험 기기 및 재료}

(1) 의료용 선형가속기 : Mevatron MX-2, Siemens, USA

(2) CR : 2000RT plus CR System, Kodak, Japan

(3) 치료계획 시스템 : Pinnacle 8.0, Philips Medicle System V 8.0 software, USA

\section{2. 실험 방법}

\section{(1) $\mathrm{CR}$ 을 이용한 의료용 선형가속기 $\mathrm{QA}$}

1) Gantry Star Shot

Gantry Star Shot은 Couch 위에 카세트를 수직으로 위치시킨 후 일정한 각도 $\left(30^{\circ}\right)$ 로 Gantry를 회전한 후 조사하는 방법으로 시행하였다.

2) Collimator Star Shot

Collimator Srar Shot은 Couch 위에 카세트를 수평으 로 위치시킨 후 일정한 각도로 Collimator를 회전한 수 조사하는 방법으로 시행하였다.

3) Light vs. Radiation Field Accuracy

조사야를 $10 \times 10 \mathrm{~cm}$ 으로 조정한 후 경계면에 칼날을 위치시키고 조사한 후 조사야를 $20 \times 20 \mathrm{~cm}$ 으로 늘리고 조사한다.

4) HDR QA(Dwell position accuracy)

카세트 윗면에 동위원소 Guide를 위치시키고 일정 간격 $(1 \mathrm{~cm})$ 로 위치하여 동위원소를 삽입하여 머물게 한 후 붕괴위치를 측정한다.

\section{(2) 처방 연동성}

현재 S병원 종양학과에서 사용 중인 OCS와 CR영상 을 PACS에서도 나타날 수 있게 구동하였다.

(3) RTP system \& PACS \& Laser printer

현재 $S$ 병원 종양학과에서 사용하고 있는 치료계획 시스템과 PACS, 그리고 Laser Printer를 연동하도록 구
성한다.

(4) Block drawing \& image의 Data 수정기능

$\mathrm{CR}$ 상에서 여러 단축 아이콘을 이용하여 차폐물의 디자인과 수정가능한지 수행하였다.

\section{(5) 영상의 부분 또는 전체 확대 기능}

영상에서 보고자 하는 부위의 부분 또는 전체의 확 대가 가능한지 수행하였다.

(6) 환자 자료의 backup 기능

내·외장 memory에 simulation image, planning image, L-gram 등의 환자 image 자료의 backup을 실시하였다.

\section{(7) 영상의 부분 또는 전체 확대 기능}

영상에서 보고자하는 부위의 부분, 또는 전체의 확 대가 가능한지 수행하였다.

(8) 필름시스템의 영상획득시간과 CR의 Scan time 비교

영상의 Scan time을 확인하여 필름시스템의 영상획 득시간을 비교하였다.

\section{II. 결 과}

Fig. 1의 CR과 PACS system을 이용하여 선형가속기 의 정도관리를 실시한 결과 Fig. 2 와 같은 영상을 획득 하였고. 영상에서 Gantry 각도의 정확도 측정이 용이 하였다. Collimator Star Shot의 영상은 Fig. 3의 이미지 로 PACS 이미지 상에서 정확성을 확인할 수 있었다.

Light vs. Radiation Field의 정확도는 Fig. 4 의 영상에 서 나타나는 것처럼 정확성을 확인할 수 있었고, $\mathrm{HDR}$ QA인 Dwell position accuracy의 검사는 Fig. 5의 영상처 럼 PACS상에서 구현됨을 알 수 있었다.

필름으로 할 수 있는 작업 자체를 $\mathrm{CR}$ 을 이용하여 모니터가 가진 소프트웨어 프로그램을 이용하여 각도 나 길이계산을 아날로그적인 방법을 거치지 않고서라 도 큰 어려움 없이 수행되어 이 부분에 대해서 $\mathrm{CR}$ 을이 용하여 모니터상에서 정확히 구현됨을 밝힐 수 있었다. 


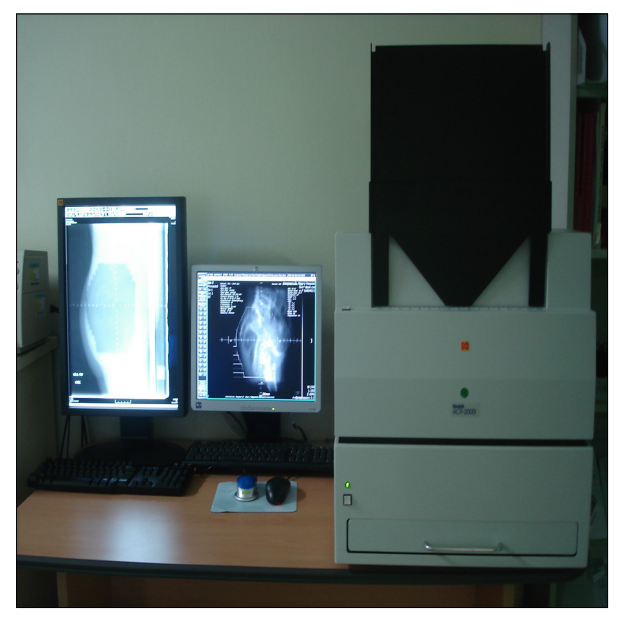

Fig 1. CR PACS

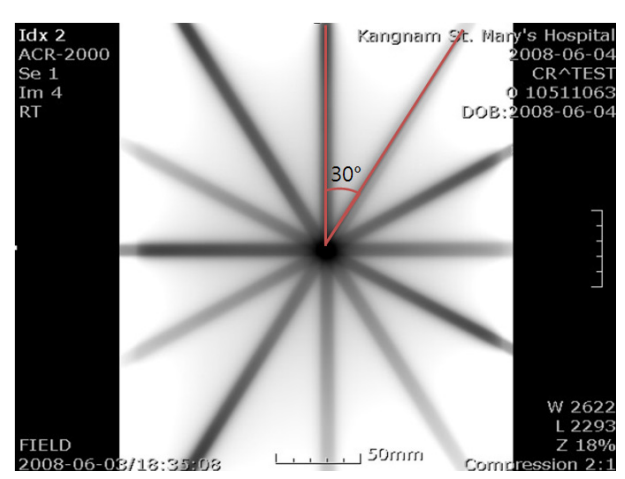

Fig 2. Gantry star shot

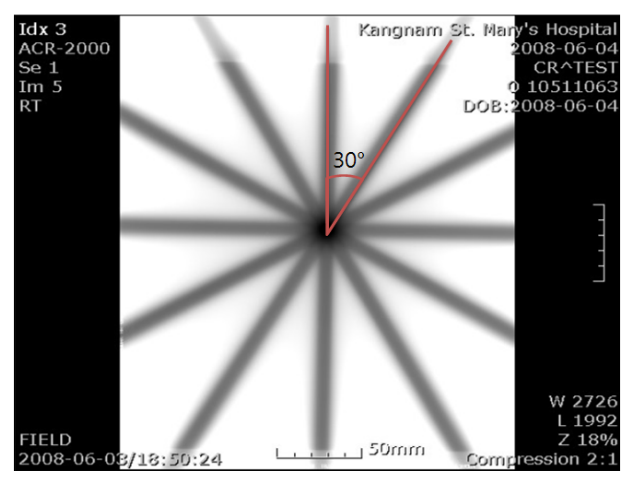

Fig 3. Collimator star shot

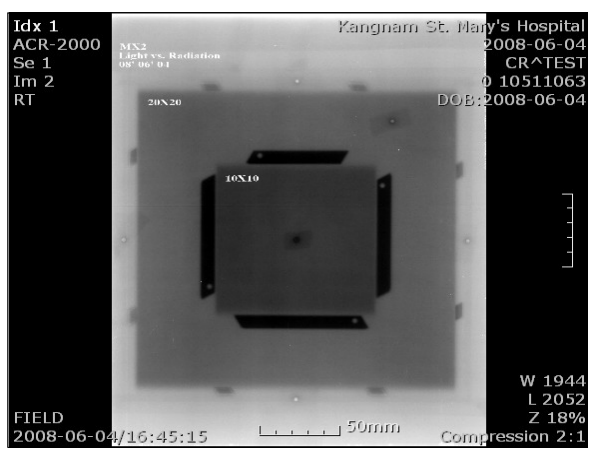

Fig 4. Light vs. Radiation Accuracy

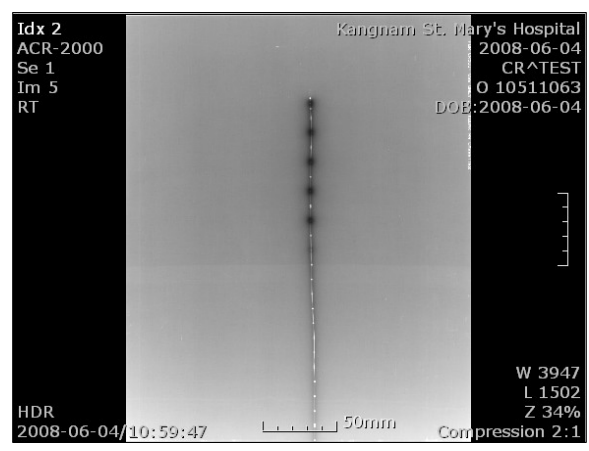

Fig 5. HDR QA: dwell position

처방의 입력은 Fig. 6 과 같이 PACS 흐름을 구축하 여 현재 $\mathrm{S}$ 병원 종양학과에서 사용 중인 $\mathrm{OCS}$ 와 $\mathrm{CR}$ 을 네트워크로 연동하여 수납에서 발생되는 CODE를 CR 상에서도 나타나게 하였다.

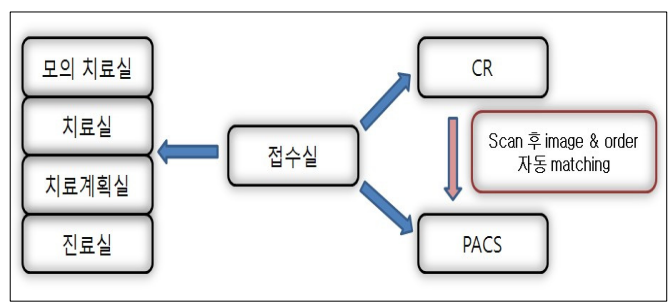

Fig 6. Order flow chart

RTP system \& PACS \& Laser printer와의 연동성을 위하여 Fig. 7 과 같이 구성하였다.

$\mathrm{S}$ 병원 종양학과에서 사용하고 있는 Planning system 인 Pinacle의 경우는 RT 영역에서 지원하는 DICOM3 파일을 지원하고 있다. 하지만 PACS에서는 DICOM 파일만 지원하기 때문에 Planning영상을 PACS상에서 
관찰이 불가능하였다. 그러나 $\mathrm{CR}$ 을 도입함으로 중간 매개체 역할을 하는 $\mathrm{CR}$ 을 통하여 Planning 영상을 전 송하고 $\mathrm{CR}$ 에서는 그 영상을 $\mathrm{PACS}$ 에서 지원하는 DICOM3 파일로 변환하여 PACS상에서도 Planning 영 상을 볼 수 있는 환경을 구축할 수 있었다.

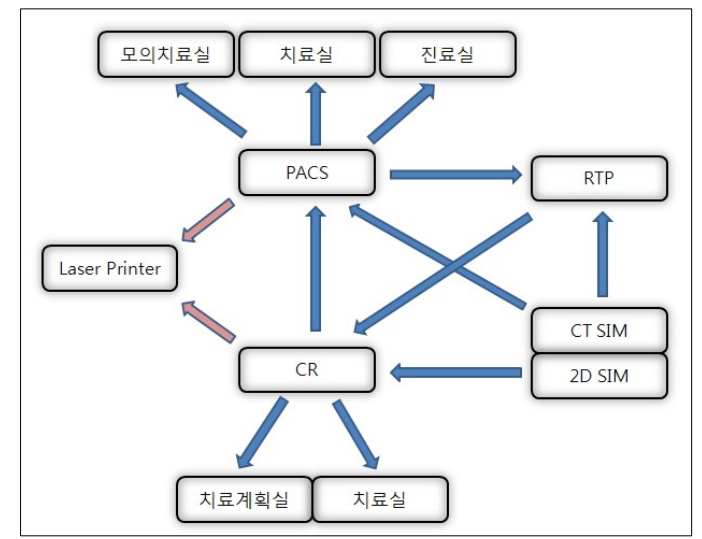

Fig 7. Patients image flow chart

방사선 종양학과에서 2차원 방사선 치료계획을 세 울 때 정상조직을 차폐하기 위해서 차폐블록모양을 이미지 상에 그려 넣고 그 이미지를 이용하여 차폐물 을 제작하여야 한다. 기존의 필름시스템에서는 Fig. 8 과 같이 작업을 수행하였으며 이는 PACS 영상에서 직 접 마우스와 단축키를 가지고 Fig. 9와 같이 필름시스 템과 동일한 작업이 가능하며 Side marking, Comment, Image verify, Field size 변경 등의 수정 \& 저장이 가능 하다. 또한 Fig. 10, Fig. 11 과 같이 영상의 확대나 축소 가 가능하여 관심영역과 표적용적을 세밀하게 관찰할 수 있었다.

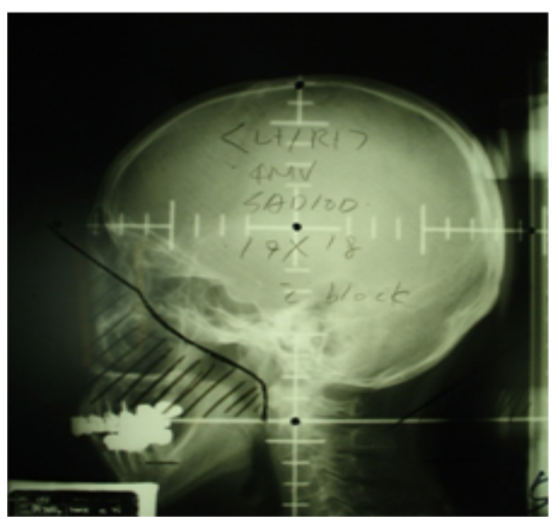

Fig 8. Block drawing with Film

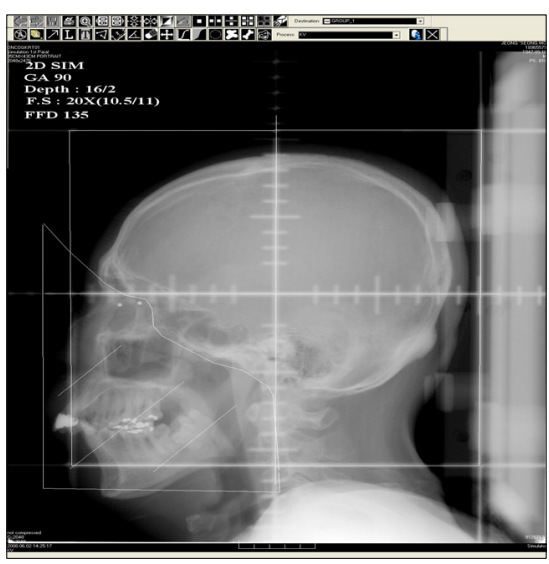

Fig 9. Block drawing by CR

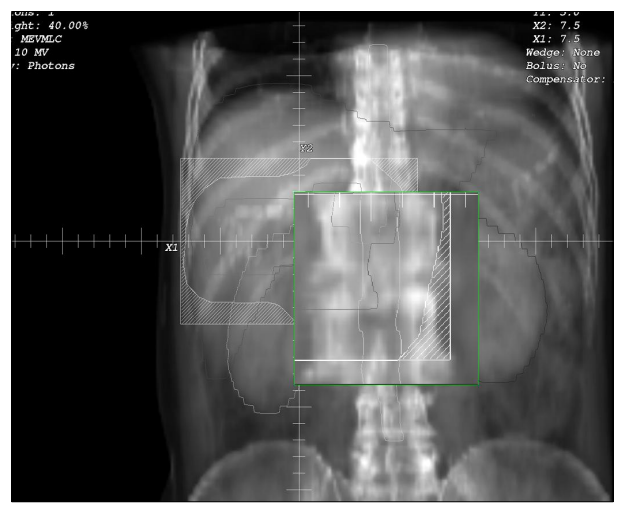

Fig 10. Partial magnified image

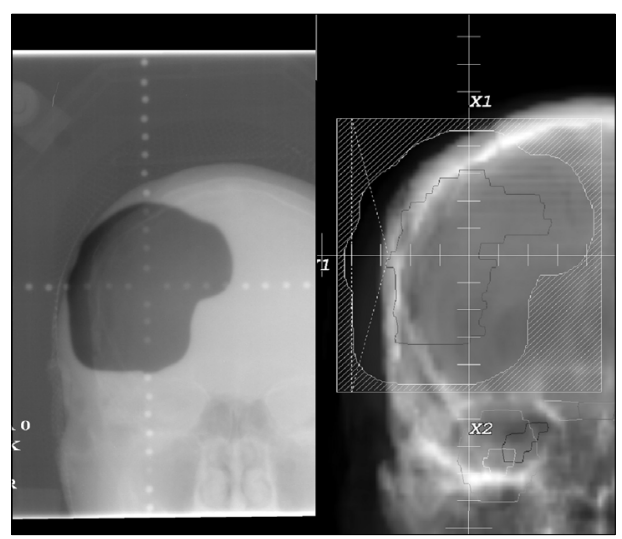

Fig 11. Full magnified image

PACS에서 환자의 영상정보에 대한 보관은 백업기 능을 이용하여 저장할 수 있고, 자유롭게 조회가 가능 
하였다. [Fig 12.]

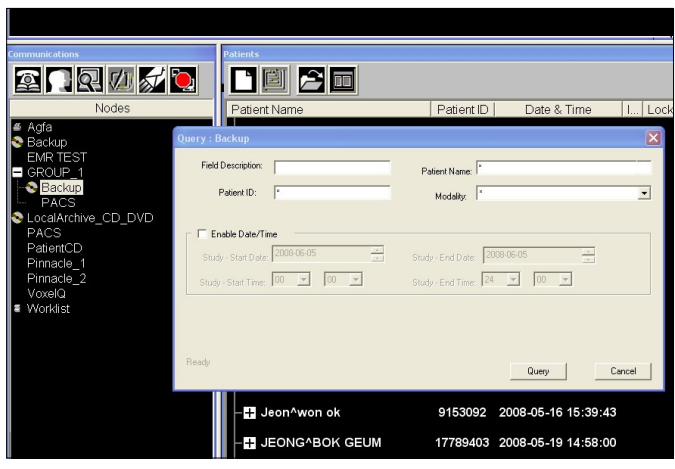

Fig 12. CR software backup windows

$\mathrm{CR}$ 을 이용하여 이미지를 얻을 경우 기존의 필름 시 스템은 90 초의 현상시간을 요구하였지만 $\mathrm{CR}$ 의 경우 Scan Time은 Low Resolution의 경우 35초, High Resolution의 경우 60 초로 이미지 획득의 시간이 현저 히 감소함을 알 수 있었고, Image Plate의 사용으로 명 실작업이 가능해졌다. 즉, Low Resolution의 경우 기존 의 필름 시스템 영상획득 시간보다 $39 \%$ 정도의 시간으 로 영상의 획득이 가능하여 방사선 종양학과에서 업 무부하를 줄일 수 있었다.

\section{II. 고 찰}

현대사회에서는 여러 가지 디지털 의료장비와 각종 의료정보 시스템, 인터넷의 활용에 따라 다양한 종류 의 의료정보와 지식이 무수히 증가하고 있고, 양질의 진료환경을 위해서 이러한 지식과 정보들을 통합 관 리하려는 필요성과 요구가 증가되고 있다 ${ }^{[5]}$. PACS가 개발된 후 김희중 등 ${ }^{[6]}$ 은 $\mathrm{PACS}$ 의 의료영상 디스플레 이 시스템에서 이러한 PACS의 확장을 시도하려는 노 력을 기울였으며 권대철 등 ${ }^{[7]}$ 은 PACS와 Web기반의 원격 병리 진단 시스템의 구동 방식을 연구하여 $\mathrm{Web}$ 기반의 PACS를 통합하는 방식을 제안하기도 하였다. 의료영상이 디지털화 되고 획득하는 영상의 수가 많 아질수록 그 영상을 통합.관리함에 있어 필름 시스템 보다는 PACS를 이용하는 것이 불필요한 인력소모의 감소, 작업시간의 단축을 이끌어내 업무효율이 증대되 었고 필름을 보관하는 공간을 작업자의 복지공간 등 으로 활용할 수 있었다.
김영우 등 ${ }^{[4]}$ 은 이러한 PACS에서 DICOM-RT와 $\mathrm{EMR}$ 의 연동을 지원하는 방사선 종양학과의 PACS 지 원을 선행하였으며, 본 연구는 S병원의 OCS과 EMR, 그리고 치료계획 시스템의 소프트웨어적인 측면이 앞 선 연구와 달랐으며 병원마다 구동되는 PACS의 시스 템적 차이가 있기에 연구를 하게 되었다.

방사선 종양학과에서의 PACS의 도입으로 인해 기 존의 필름 시스템으로 시행하였던 의료용 선형가속기 의 QA(Gantry Star Shot, Collimator Star Shot, Light vs. Radiation Field accuracy)와 HDR QA(Dwell position accuracy)를 시행 ${ }^{[8]}$ 할 수 있었으며 기존의 필름과 $\mathrm{View}$ Box로 확인했던 사항들을 모니터 화면을 통하여 마우 스와 같은 입력장치로 각도확인이나 거리확인이 가능 하였을 뿐 아니라 모니터 영상에서 정상조직을 보호 하는 차폐물을 제작하기 위한 블록 drawing이 가능하 였다. 더욱이 부분 확대와 전체 확대 기능은 기존의 필름에서는 할 수 없는 큰 장점으로 부각되며 정상조 직이나 이상병변의 구체적인 관찰이 용이하였다.

CR에서 얻어지는 영상은 RTP system 과 PACS, OCS 를 통합으로 연결하여 동 시간에 다른 위치에서 영상 을 확인할 수 있었다. 또한 획득된 영상은 백업기능을 통하여 영상을 영구적으로 저장할 수 있었으며 필요 할 때는 언제든지 과거의 영상을 검색할 수 있고, 손 쉽게 접근할 수 있었다.

이러한 장점에도 불구하고 PACS를 통하여 모니터 로 나타나는 디지털 영상에서는 몇 가지 제한점을 가 지고 있다.

Brody WR ${ }^{[9]}$ 은 디지털영상은 일반 방사선 사진에 비 해 해상도가 낮다는 단점을 지적하였으나. Ishida 등 [10] 이 디지털변환 시에 진단정보의 손실은 극히 적으며 디지털영상의 대조도와 흑화도를 관찰자가 임의로 조 절할 수 있으므로 이러한 방사선 사진에서 관찰하기 어려운 병변까지 검출할 수 있어 이러한 단점을 극복 할 수 있다고 보고된 바가 있다.

최진우 등 ${ }^{[11]}$ 은 디지털영상 시스템에도 사용자 간 진단할 수 있는 능력의 차이가 있으며, 이를 인지하고 평가할 필요도 있기 때문에 이를 활용한 진단/판독 측 면에 더 많은 노력이 경주되어야 한다고 주장하였으 며 전문의는 디지털영상 시스템의 단점 또한 인지하 
여야 하며, 제조사에서는 PACS에서 필요한 시스템을 개발할 수 있도록 계속적인 피드백이 필요하다고 보 고하였다.

Full PACS System은 많은 투자와 장비가 필요하며 모든 작업이 컴퓨터를 통해 이루어지며 전자기록과 전자서명에 대한 법적인 보장 등이 향후 해결되어야 할 점이라고 주장하였으며 ${ }^{[12]}$, 모든 종사자는 항상 환 자의 정보에 관한 보안에 신경을 써야 할 것이다.

현재에는 부분적인 RT PACS System환경으로 제약 이 있지만 향후 방사선 치료 영역에서는 FULL RT PACS System 적용으로 Planning 영역에서 발생되는 RT Structure 및 RT Dose등과 같은 영상도 PACS를 이용하 여 관찰할 수 있는 환경을 형성해야 될 것으로 예상되 며 이러한 점은 PACS 도입으로 인하여 방사선 종양학 과 뿐만 아니라 병원 전체에 얻어지는 큰 이점이라고 사료된다.

\section{II. 결 론}

PACS System은 도입함에 있어 비용과 시간이 많이 들고 계속적인 소프트웨어 및 시스템의 피드백이 필 요하다. 방사선 종양학과의 PACS System 구축의 결과 기존의 Film System을 이용했을 경우보다 업무시간이 단축되었으며 필름의 저장공간을 여유공간으로 활용 할 수 있었고 의료용 선형가속기 및 $\mathrm{HDR}$ 의 디지털 영상에서의 정도관리가 가능해졌으며 차폐블록의 제 작도 가능해졌다. 또한 환자의 대기시간이 단축되었으 며 환자의 영상 정보를 동시간대 다른 위치에서 확인 이 가능해졌다. 이러한 편리한 접근성은 보안이 필수 적이며 향후 Full PACS System이 적용될 시에는 전자 기록과 전자서명에 대한 법적보장이 해결되어야 한다. 또한 종사자들이 환자 정보에 쉽게 접근할 수 있으므 로 이들 모두는 환자 정보 보호를 위해 신경을 써야 할 것으로 사료된다.

\section{Reference}

[1] 권달관, 권대철, 김기홍 등, 의료영상정보학, 청구문화사, pp.420-439, 2010.

[2] 전필현, $\mathrm{PACS}$ 의 기본개요, 대한 PACS 학회지, 2005.

[3] 곽병준, 국진선, 김경근 등, 방사선개론, 현문사, pp. 291-295,
2011.

[4] 김영우, 김종효, 정천기 등, DICOM-RT와 EMR 연동을 지원하는 방사선종양학 PACS의 구현, 대한 PACS 학회지, Vol. 15, No. 1, pp.52-59, 2009.

[5] 김대근, 한준구, 심정석 등, 병원내의 멀티미디어 데이터: PACS확장을 위한 고려사항, 대한 PACS 학회지, Vol. 8, No. 1, pp.11-16, 2002.

[6] 김희중, 이창래, PACS와 의료영상디스플레이 시스템, 한국정밀공학회지, Vol. 25, No. 1, pp.183-195, 2008.

[7] 권대철, 변호영, 엄준회 등, Web 기반의 원격 병리 진단 시스템과 PACS의 비교, 대한 PACS 학회지, Vol. 7, No. 1, pp.25-33, 2001.

[8] Faiz M. Khan, The Physics of Radiation Therapy, Lippincott Williams \& Wilkins, USA, 3rd Edition, pp.424-454, 2001.

[9] Brody WR, Digital radiography, Raven Press, pp.1-82, 181-202, 1984.

[10] Ishida M, Doi K, Loo Ln, etc, Digital image processing : Effect on detectibility of simulted low contrast radiographic patterns, Radiology, Vol. 150, pp.569-575, 1984.

[11] 최진우, 이원진, 디지털 방사선영상 시스템의 기본적 원리, 대한구강악안면방사선학회지, Vol. 1 No. 40, pp. 155-158, 2010.

[12] 허승재, 안용찬, 임도훈 등, 디지털 화상 병력 시스템과 디지털 방사선 치료기록 시스템의 개발과 사용 경혐, 대한방사선종양학회지, Vol. 18, No. 1, pp.67-72. 2000. 